\title{
N-terminal functional region of the invariant chain efficiently targets the binding of a CTL epitope to MHC class I molecules during cross-presentation
}

\author{
C. Wu, D.G. Zhang, F.F. Chen, X.L. Liu, S.J. Liu and W.Y. Yu \\ Key Laboratory of Zoonoses of Anhui Province, Anhui Agricultural University, \\ Hefei, China \\ Corresponding author: W.Y. Yu \\ E-mail: yuwy@ahau.edu.cn
}

Genet. Mol. Res. 13 (2): 2438-2450 (2014)

Received May 6, 2013

Accepted September 13, 2013

Published April 3, 2014

DOI http://dx.doi.org/10.4238/2014.April.3.16

\begin{abstract}
Cross-presentation (CP) is important for priming $\mathrm{T}$ cell responses to many viral, bacterial, and tumor antigens. Here, we designed two Ii mutants, based on evidence that the invariant chain ( $\mathrm{Ii}$, also named CD74) binds newly synthesized MHC class I molecules with the class II-associated invariant chain peptide (CLIP) region of Ii, which occupies the peptide-binding groove. Specifically, we designed (1) Ii-O257, which is a CLIP-substituted Ii chimer, in which OVA257-264 (SIINFEKL) was substituted for CLIP, and (2) Ii-, also named CT257, which is a C-terminal truncated form of Ii-O257 that contains the N-terminal flanking region of Ii. We immunized C57BL/6 mice with these recombinant proteins. Real-time PCR detected that mice immunized with either Ii-O257 or Ii-CT257 recombinant proteins exhibited increased IFN- $\gamma$ mRNA expression (approximately 11fold and 13-fold, respectively) and increased IL-2 mRNA expression (approximately 9-fold and 11-fold, respectively), compared to mice immunized with the OVA257-264 peptide. In vivo cytokine analysis
\end{abstract}


showed that recombinant Ii proteins were highly efficient at activating $\mathrm{T}$ cells. Confocal microscopy and co-immunoprecipitation showed that the 2 Ii-OVA257-264 chimers are associated intracellularly with $\mathrm{H}-2 \mathrm{~K}^{\mathrm{b}}$ molecules. Thus, Ii-CT257 (amino acids 1-89) binds stably to MHC class I with high affinity, indicating that it is a minimal functional fragment of the Ii immune vector. In conclusion, the N-terminal functional region of the Ii fusion protein containing CTL epitopes might prove to be useful for developing peptide or DNA vaccines that use $\mathrm{CP}$ as the main mechanism for $\mathrm{CD} 8^{+} \mathrm{T}$ cell stimulation.

Key words: Cross-presentation; MHC class I; Invariant chain; CTL epitope; RT-PCR; Colocalization

\section{INTRODUCTION}

$\mathrm{CD}^{+} \mathrm{T}$ cells play a critical role in the control of viral and intracellular bacterial infections and cancer. In the case of viruses, $\mathrm{CD} 8^{+} \mathrm{T}$ cells are activated through the $\mathrm{T}$ cell receptor by recognizing short viral peptides presented in the context of MHC class I molecules (Townsend et al., 1985, 1986). Unlike the classical MHC class I antigen-presentation pathway, $\mathrm{T}$ cell responses are efficiently generated to target pathogens that are restricted to the endocytic pathway, and never reach the cytosol (Kaleab et al., 1990). Professional antigen-presenting cells (pAPCs), particularly dendritic cells (DCs), process and present exogenously derived antigens to MHC class I molecules (Yewdell et al., 1999; Heath and Carbone, 2001). This process is termed cross-presentation (CP) (Bevan, 1976; Norbury and Sigal, 2003), and it might be important for initiating $C D 8^{+} T$ responses against tumors and pathogens that do not infect pAPC (Sigal et al., 1999; Larsson et al., 2001). Consequently, there is considerable interest in understanding how to augment MHC class I presentation efficiency in CP.

Antigen-specific $\mathrm{CD} 8^{+} \mathrm{T}$ cell responses are largely dependent on antigen dose and type (Zinkernagel and Hengartner, 2001; Langenkamp et al., 2002). Synthetic peptides that correspond to $\mathrm{T}$ cell epitopes might represent ideal subunits for safe vaccines. Unlike directpresentation, however, ovalbumin (OVA)257-264 synthesized as a minimal determinant is not a substrate for CP (Ma et al., 2009). This important observation indicates that CP does not result from the transfer of the minimal determinant sequence. Furthermore, recent studies have shown that the presentation of MHC class I epitopes is a relatively inefficient process (Princiotta et al., 2003; Lehner and Cresswell, 2004). Therefore, vaccines that elicit CD8 ${ }^{+} \mathrm{T}$ cell responses could be improved.

An unexpected interaction between the MHC class II accessory molecule Ii and MHC class I was first described by Cerundolo and colleagues (Cerundolo et al., 1992). Ii acts as a chaperone, and guides MHC class II molecules to endocytic vesicles during biosynthesis (Bakke and Dobberstein, 1990). It also binds MHC class I molecules in the endoplasmic reticulum (ER), and targets a fraction of MHC class I molecules in the endocytic compartment to function in cross-presentation (Sugita and Brenner, 1995; Basha et al., 2012). The class II invariant chain-derived peptide (CLIP) mediates interactions between Ii and class I molecules (Powis, 2006; van Luijn et al., 2012). If the CLIP region of genetically engineered 
Ii was replaced with a T helper (Th) epitope, it could function efficiently to stimulate specific T cell lines (van Bergen et al., 1997; Fujii et al., 1998; Gao et al., 2006). In addition, the residues Asn-Asp (DN), which lay just outside the C-terminal of CLIP (Figure 1a), might promote the association of Th epitopes with the peptide-binding site, as shown in our previous study (Chen et al., 2012).

In this study, we used chicken OVA and recombinant Ii protein (Ii-O257), in which CLIP was replaced with OVA257-264 peptide [which is a class I $\left(\mathrm{K}^{\mathrm{b}}\right)$-restricted epitope of OVA], to test whether the versatile Ii vector could promote cytotoxic T lymphocyte (CTL) epitope presentation by CP. Furthermore, we constructed truncated Ii-O257 and termed Ii-CT257, to explore a minimal functional fragment of the Ii vector. We also evaluated the validity of immunization by recombinant protein Ii-CT257. This study is anticipated to have important implications for the use of the versatile Ii vector in developing new vaccines against cancer and viral infections.

\section{MATERIAL AND METHODS}

\section{Generation of recombinant Ii constructs}

cDNA coding for murine Ii p31 in our previous study (Chen et al., 2012) was used as a cassette vector in which the CLIP-encoding sequence may be replaced with immunodominant OVA peptide SIINFEKL, OVA257-264. The sequence of the double-stranded oligonucleotides was as follows: 5'-AGTATAATCAACTTTGAAAAACTG-3', 5'-CAGTTTTCAAAGTTATT ATACT-3'. Based on overlap extension polymerase chain reaction (PCR), an OVA257264 fragment was engineered onto the CLIP region to generate Ii-OVA chimer. Then, a C-terminal truncated Ii (Ii1-89), containing the cytosolic (Cyt) and transmembrane domain (TM), OVA257-264 sequence and DN, was obtained by PCR using the Ii-OVA chimer as a template. The resulting constructs were termed Ii-O257 and Ii-CT257, respectively (Figure 1). The $\mathrm{H}-2 \mathrm{~K}^{\mathrm{b}}$ sequence was amplified from $\mathrm{C} 57 \mathrm{BL} / 6$ mice. All primers used for PCR and all constructed vectors are shown in Table 1 . These eukaryotic expression Ii constructs were inserted into pmCherry- $\mathrm{C} 1$ and the $\mathrm{H}-2 \mathrm{~K}^{\mathrm{b}}$ gene was inserted into pEGFP-N1, to examine localization by confocal microscopy. Likewise, the Ii constructs were cloned into prokaryotic expression vector $\mathrm{pET} 32 \mathrm{a}$ to produce immunization antigens. Ii constructs were cloned into PCMV-Myc for identification by immunoprecipitation and Western blotting. The validity of these constructs was confirmed by DNA sequencing.

\section{Proteins and peptides}

Escherichia coli expression strain, Rosetta, was transformed with each pET32a-Ii construct. Bacteria were incubated at $37^{\circ} \mathrm{C}$ in Luria-Bertani broth containing $50 \mathrm{mg} / \mathrm{ml} \mathrm{am}$ picillin, and protein expression was induced with $1 \mathrm{mM}$ isopropyl $\beta$-D-thiogalactoside at an $\mathrm{OD}_{600}$ of 0.4. Four hours after induction, the cells were harvested and the bacterial pellet was resuspended in phosphate-buffered saline (PBS) with protease inhibitors. The cells were sonicated, and the lysate was cleared for $15 \mathrm{~min}$ at $12,000 \mathrm{~g}$, and filtered through a $0.45 \mu \mathrm{m}$ filter. Cleared lysate from $1 \mathrm{~L}$ of induced culture was applied to $2 \mathrm{~mL}$ Ni Sepharose ${ }^{\mathrm{TM}} 6$ Fast Flow resin (GE Healthcare, Waukesha, USA) at a flow rate of $1 \mathrm{~mL} / \mathrm{min}$. The column was washed 
4 times with binding buffer containing $20 \mathrm{mM}$ imidazole, and eluted in binding buffer containing $300 \mathrm{mM}$ imidazole. The eluted samples were desalted by a PD-10 desalting column (GE Healthcare, Waukesha, USA), and stored at $-70^{\circ} \mathrm{C}$. A synthetic peptide corresponding to amino acid residues 257-264 (SIINFEKL) of OVA was obtained from Genscript (Nanjing, China). OVA protein was purchased from Sigma (USA).

\section{Mice and immunization}

Female C57BL/6 mice were obtained from the Animal Centre of Anhui Medicine University, China, and bred under specific pathogen-free conditions. All experimental procedures were performed following the Anhui Medicine University Animal Care Guidelines under an approved protocol. Mice between 8 and 10 weeks in age were divided into 5 groups and used for immunization. To immunize mice, shaved abdominal skin was wiped with $70 \%$ ethanol. Five C57BL/6 female mice were immunized with $100 \mu \mathrm{g}$ of each peptide or protein antigen and complete Freund's adjuvant at a 1:1 ratio (day 0). Control animals were immunized with PBS only. All mice were boosted twice at 2-week intervals with the same amount of antigen. Two weeks after the last immunization, mice were sacrificed by cervical dislocation, and the spleens were excised from all immunized and control mice.

\section{Quantification of cytokine mRNAs by real-time PCR (RT-PCR)}

Total RNA was extracted from different mouse spleens. Isolated spleens were immediately used, or were frozen in liquid nitrogen and stored at $-80^{\circ} \mathrm{C}$ until use. RNA extraction from the spleens was performed using RNAiso Plus (TaKaRa Biotechnology Co., China). Single-stranded cDNA from $1 \mu \mathrm{g}$ of RNA was synthesized by the PrimeScript ${ }^{\mathbb{B}}$ RT reagent Kit (TaKaRa Biotechnology Co.). RT-PCR was performed on a IQ5 ${ }^{\mathrm{TM}}$ Real-Time Detection System (Bio-Rad, USA) using SYBR ${ }^{\circledR}$ Green I (TaKaRa Biotechnology Co.) as a doublestrand DNA-specific binding dye. For the detection of interferon (IFN)- $\gamma$ and interleukin (IL)2, primers were designed using Primer Express (PE Applied Biosystems, Foster City, USA) (Table 1). Normalization was performed by amplifying murine $\beta$-actin housekeeping mRNA (Table 1). For all target genes, identical thermal cycling conditions were used: $5 \mathrm{~s}$ at $95^{\circ} \mathrm{C}$ and $30 \mathrm{~s}$ at $60^{\circ} \mathrm{C}$. The 2-step PCR reactions were cycled 40 times after initial denaturation at $95^{\circ} \mathrm{C}$ for $30 \mathrm{~s}$. Amplification was performed in triplicate in a total volume of $25 \mu \mathrm{L}$ containing $0.4 \mu \mathrm{M}$ of each primer, $12.5 \mu \mathrm{L}$ SYBR $^{\circledR}$ Premix Ex Taq II (2X), and $3 \mu \mathrm{L}$ 1:20 diluted cDNA. Relative mRNA quantitation was performed by the comparative $\Delta \Delta \mathrm{C}_{\mathrm{T}}$-method. The relative quantification of target, normalized to an endogenous reference, ( $\beta$-actin) and a relevant control, was determined as follows:

$$
\begin{aligned}
& \text { relative quantitation }=2^{-\Delta \Delta \mathrm{CT}} \\
& \Delta \Delta C_{T}=\Delta \mathrm{C}_{\mathrm{T} \text { (experimental sample) }}-\Delta \mathrm{C}_{\mathrm{T} \text { (control) }} \\
& \Delta C_{T}=\mathrm{C}_{\mathrm{T}(\mathrm{IFN}-\gamma, \mathrm{IL}-2)}-\mathrm{C}_{\mathrm{T}(\beta-\text { actin })}
\end{aligned}
$$

where $\Delta \Delta C_{T}$ was defined as the difference in mean $\Delta \mathrm{C}_{\mathrm{T} \text { (experimental sample) }}$ and mean $\Delta \mathrm{C}_{\mathrm{T}}$ (control);

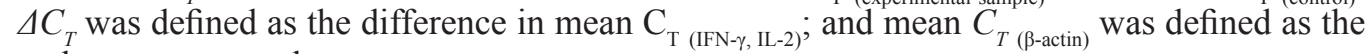
endogenous control. 


\section{Cell culture, transfection, and confocal microscopy}

COS7 cells were obtained from the Biology Science College, University of Science and Technology of China. The cells were grown at $37^{\circ} \mathrm{C}$ in $5 \% \mathrm{CO}_{2}$ in standard culture medium (Dulbecco's Modified Eagle's Medium, DMEM) supplemented with 10\% fetal bovine serum and antibiotics ( $50 \mathrm{U} / \mathrm{mL}$ penicillin and $50 \mathrm{mg} / \mathrm{mL}$ streptomycin). COS7 cells were cultured in 24-well plates, and transfected at 50-80\% confluency. Transient transfections were performed with Xfect ${ }^{\mathrm{TM}}$ polymers (Clontech Laboratories, USA) following manufacturer protocols. After $4 \mathrm{~h}$ at $37^{\circ} \mathrm{C}$, nanoparticle complexes were removed and replaced with fresh complete growth medium. After $24 \mathrm{~h}$, images of COS7 cells were acquired with a Zeiss confocal laser scanning microscope (CLSM) using a 60X oil objective [excitation at $488 \mathrm{~nm}$ for red fluorescent protein and emission at $515 \mathrm{~nm}$ for green fluorescent protein (GFP)].

\section{Co-immunoprecipitation and Western blotting}

COS7 cells seeded in 25- $\mathrm{cm}^{2}$ plates were co-transfected with fusion genes pEGFP-N1$\mathrm{H}-2 \mathrm{~K}^{\mathrm{b}}$, Myc-Ii, Myc-Ii-O257, and Myc-Ii-CT257. At $48 \mathrm{~h}$ post-transfection, the cells were washed, harvested, and lysed on ice for $1 \mathrm{~h}$ in lysis buffer $(50 \mathrm{mM}$ Tris- $\mathrm{HCl}, 150 \mathrm{mM} \mathrm{NaCl}$, $1 \%$ Nonidet P40, and $0.5 \%$ sodium deoxycholate, a protease inhibitor cocktail). The precleared lysates were split and incubated with $5 \mu \mathrm{g}$ purified anti-GFP mAb (Zhongshan, China) for $1 \mathrm{~h}$ at $4^{\circ} \mathrm{C}$. Immunocomplexes were isolated using $50 \mu \mathrm{L}$ Protein A/G Plus-Agarose beads at $4^{\circ} \mathrm{C}$ overnight. The resins were then recovered by centrifugation at $12,000 \mathrm{~g}$ for $20 \mathrm{~s}$, and washed twice with cell lysis buffer and buffer $2(50 \mathrm{mM}$ Tris- $\mathrm{HCl}, 500 \mathrm{mM} \mathrm{NaCl}, 0.1 \%$ Nonidet P40, $0.05 \%$ sodium deoxycholate), with centrifugation following each wash. Subsequently, the pellets were washed with buffer 3 ( $10 \mathrm{mM}$ Tris-HCl, $0.1 \%$ Nonidet P40, $0.05 \%$ sodium deoxycholate). After the final wash, the pellets were resuspended in $60 \mu \mathrm{L} 1 \mathrm{X}$ SDS loading buffer, heated at $100^{\circ} \mathrm{C}$ for $3 \mathrm{~min}$, and subjected to sodium dodecyl sulfate polyacrylamide gel electrophoresis (SDSPAGE), with whole-lysate tracks included as controls. Resulting immunoblots were incubated with anti-Myc primary antibody overnight at $4^{\circ} \mathrm{C}$, followed by horseradish peroxidase (HRP)coupled secondary reagents and an ECL detection system (Pierce, IL, USA).

\section{Statistical analysis}

All results comparing immunized nice and control mice were analyzed using the paired Student $t$-test. These data are reported as mean $\pm \mathrm{SE}$, and were considered to be significant if $\mathrm{P}<0.05$

\section{RESULTS}

\section{Construction and identification of Ii/OVA hybrids}

The murine p31 Ii cDNA clones were previously described (Chen et al., 2012). We constructed a CLIP-replaced Ii hybrid, in which the CLIP region had been substituted with an OVA257-264 epitope. The nucleotides covering the CLIP region in the Ii cDNAs were removed and replaced by a double-stranded oligonucleotide encoding SIINFEKL peptide. Then, a C-terminal truncation of the Ii chimer (amino acids 1-89) was obtained by PCR on the basis of the Ii-OVA chimer. Figure 1a presents a schematic of the 2 hybrids, Ii-O257 and Ii-CT257. After identifica- 
tion with electrophoresis and sequencing, Ii-O257 and CT-O257 (Figure 1b) were subcloned into the eukaryotic expression vectors, pmCherry-C1 and pCMV-Myc. For the production of immunization antigens, the hybrids were also inserted into the prokaryotic expression vector pET-32a. The expressed recombinant proteins were purified and identified (Figure 1c). In addition, the $\mathrm{H}-2 \mathrm{~K}^{\mathrm{b}}$ gene (Figure $1 \mathrm{~b}$ ) was amplified and cloned into eukaryotic expression vector $\mathrm{pEGFP}-\mathrm{N} 1$. pmCherry-C1-Ii/Ii-O257/Ii-CT257 and pEGFP-N1-H-2K ${ }^{\mathrm{b}}$ were used for CLSM. pCMV-MycIi/Ii-O257/Ii-CT257 and pEGFP-N1-H-2K ${ }^{\mathrm{b}}$ were used for transfection, co-immunoprecipitation, and Western blotting. Primers used for PCR and the construction of vectors are shown in Table 1.

\section{a}
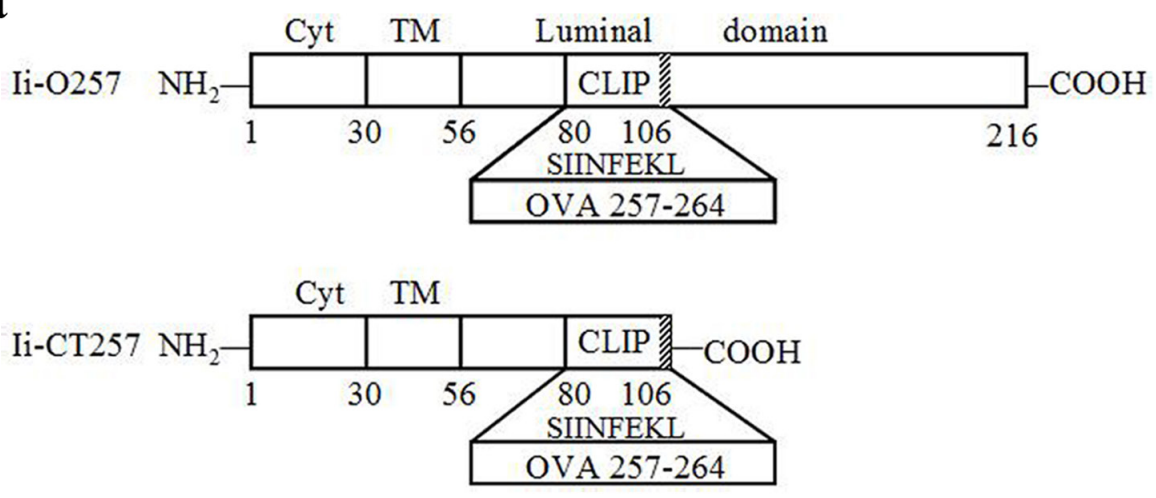

b

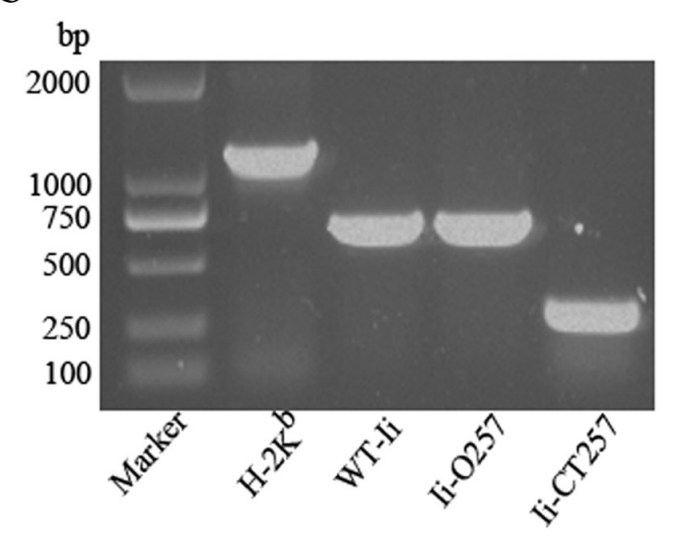

C

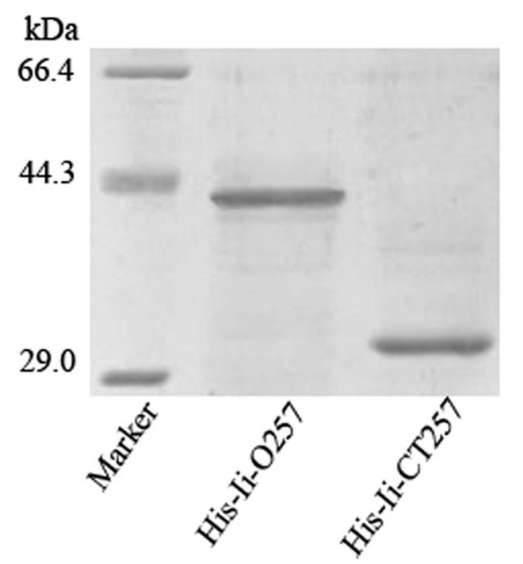

Figure 1. Construction, expression and purification of li/OVA hybrids and cloning of the H-2K $\mathrm{K}^{\mathrm{b}}$ gene. a. Schema of CLIP-replaced murine Ii constructs prepared in this study. Full-length Ii consists of a cytosolic domain (Cyt), transmembrane domain (TM) and luminal domain that contains the CLIP segment. The double-stranded oligonucleotide encoding OVA257-264 was replaced with the CLIP region to generate Ii-O257. The C-terminal truncation of Ii-O257 chimer generated Ii-CT257. The region shown by the hatched box is the DN (Asn-Asp) residues, the C-terminal segment of CLIP. b. PCR-amplified gene and Ii variant products: H-2K ${ }^{\mathrm{b}}$, wild-type (WT) Ii, Ii-O257 and Ii-CT257. c. SDS-PAGE analysis of expressed and purified products. PCR-amplified Ii-O257 and Ii-CT257 were inserted into expression vectors pET-32a to make immunization antigens. Purified products: HisIi-O257, His-Ii-CT257. 
Table 1. Primer sequences and constructed vectors in this study.

\begin{tabular}{|c|c|c|c|}
\hline No. & Primer sequences $\left(5^{\prime}-3^{\prime}\right)$ & Amplicon length (bp) & Constructed vectors \\
\hline 1 & $\begin{array}{l}\text { Forward: 5'-cccgaattctgatggtaccgtgcacgctgctcctgctgt-3' } \\
\text { Reverse: } 5 \text { '-gcgtcgactgcgctagagaatgagggtc-3' }\end{array}$ & 1107 & pEGFP-N1-H-2K ${ }^{b}$ \\
\hline 2 & $\begin{array}{l}\text { Forward: 5'-ccgctcgagctatggatgaccaacgcg-3' } \\
\text { Reverse: } 5^{\prime} \text {-ccggaattcgatcacagggtgacttgacc-3' }\end{array}$ & 648 & pmCherry-C1-Ii \\
\hline 3 & $\begin{array}{l}\text { Forward: 5'-ccggaattcggatggatgaccaacgcgac-3' } \\
\text { Reverse: } 5^{\prime} \text {-ccgctcgagtcacagggtgacttgacc-3' }\end{array}$ & 648 & pCMV-Myc-Ii \\
\hline 4 & $\begin{array}{l}\text { Forward1: 5'-ccgctcgagctatggatgaccaacgcg-3' } \\
\text { Reverse1: 5'-cagttttcaaagttgattatacttttcatgcgaaggctctc-3' } \\
\text { Forward2: 5'-agtataatcaactttgaaaaactggataatgctccttgggc-3' } \\
\text { Reverse2: 5'-ccggaattcgatcacagggtgacttgacc-3' }\end{array}$ & 600 & pmCherry-C1-Ii-O257 \\
\hline 5 & $\begin{array}{l}\text { Forward: 5'-ccgctcgagctatggatgaccaacgcg-3' } \\
\text { Reverse: } 5 \text { '-ccggaattcgagttatccagttttcaaag-3' }\end{array}$ & 267 & pmCherry-C1-Ii-CT257 \\
\hline 6 & $\begin{array}{l}\text { Forward: 5'-ccggaattcggatggatgaccaacgcgac-3' } \\
\text { Reverse: } 5^{\prime} \text {-ccgctcgagtcacagggtgacttgacc-3' }\end{array}$ & 600 & pCMV-Myc-Ii-O257 \\
\hline 7 & $\begin{array}{l}\text { Forward: 5'-ccggaattcggatggatgaccaacgcgac-3' } \\
\text { Reverse: } 5 \text { '-ccgctcgagtcagttatccagttttcaaag-3' }\end{array}$ & 267 & pCMV-Myc-Ii-CT257 \\
\hline 8 & $\begin{array}{l}\text { Forward: 5'-ccggaattcatggatgaccaacgcgac-3' } \\
\text { Reverse: 5'-ccgctcgagtcagggtgacttgacccag-3' }\end{array}$ & 600 & pET-32a-Ii-O257 \\
\hline 9 & $\begin{array}{l}\text { Forward: 5'-ccggaattcatggatgaccaacgcgac-3' } \\
\text { Reverse: 5'-ccgctcgagtgttatccagttttcaaag-3' }\end{array}$ & 267 & pET-32a-Ii-CT257 \\
\hline 10 & $\begin{array}{l}\text { Forward: } 5 \text { '-cccaggatgctcacttca-3' } \\
\text { Reverse: } 5 \text { '-ccgcagagtccaagttca3-' }\end{array}$ & 93 & IL-2 \\
\hline 11 & $\begin{array}{l}\text { Forward: 5'-cggcacagtcattgaaagccta-3' } \\
\text { Reverse: } 5 \text { '-gttgctgatggcctgattgtc-3' }\end{array}$ & 199 & IFN- $\gamma$ \\
\hline 12 & $\begin{array}{l}\text { Forward: 5'-catccgtaagacctctatgccaac-3' } \\
\text { Reverse: 5'-atggagccaccgatccaca-3' }\end{array}$ & 171 & $\beta$-actin \\
\hline
\end{tabular}

\section{Cytokines produced by spleen cells from mice immunized with recombinant pro- teins Ii-O257-264}

Antigen-activated $\mathrm{CD} 8^{+} \mathrm{T}$ cells produce a wide variety of cytokines. To examine whether Ii-O257 and Ii-CT257 induced a specific immune response in vivo, we immunized $\mathrm{C} 57 \mathrm{BL} / 6$ mice with these recombinant proteins. Then we examined specific IFN- $\gamma$ and IL-2 production by spleen cells from mice immunized with Ii-O257 or IiCT257, and compared them with those from mice immunized with OVA protein and OVA257-264 peptide. Cytokine mRNA levels were determined by RT-PCR, as previously described (Brink et al., 2000). As shown in Figure 2, mice immunized with IiO257 or Ii-CT257 recombinant proteins produced a higher amount of IFN- $\gamma$ (11-fold and 13-fold, respectively) compared to those immunized with OVA257-264 peptide; however, the IFN- $\gamma$ levels were lower compared to those in mouse immunized with OVA protein + CFA (21-fold). IFN- $\gamma$ levels produced by spleen cells from mice immunized with OVA257-264 peptide + CFA were quite low. The level of IL-2 in the spleen cells of each group followed the same trend as IFN- $\gamma$. Of particular interest, immunization with Ii-CT257 induced slightly higher levels of cytokines compared to those from Ii-O257 protein immunization. These results indicate that immunization with either Ii-O257 or Ii-CT257 protein induces the activation of $\mathrm{CD}^{+} \mathrm{T}$ cells, and that Ii-CT257 was comparatively more effective than Ii-O257 at inducing cellular immunity. IFN- $\gamma$ enhances the induction of $\mathrm{CD}^{+} \mathrm{CTLs}$ or the killing activity of macrophages. In addition, the amount of IL-2 secreted by antigen-activated CTLs might be sufficient to induce their own proliferation and differentiation. 


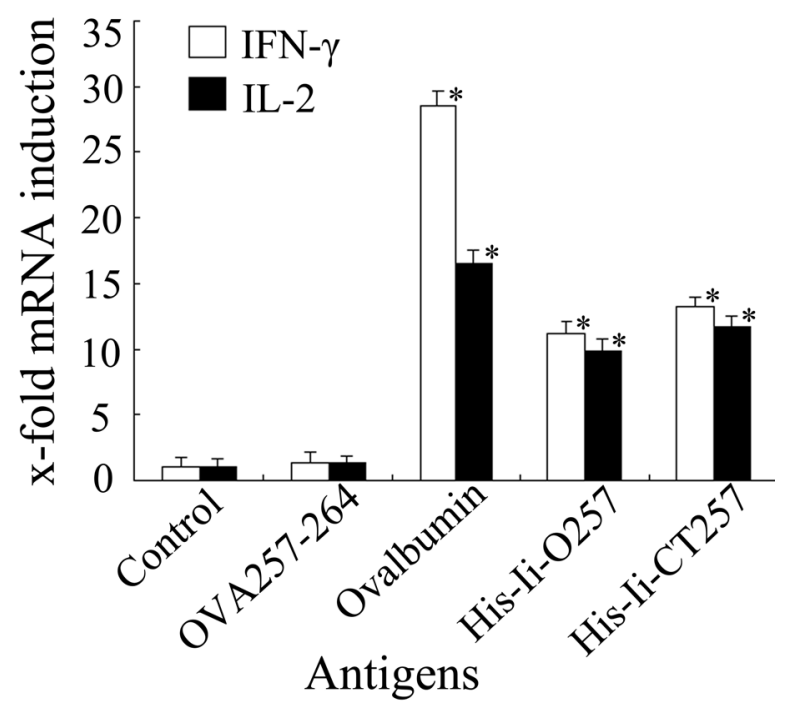

Figure 2. Quantitative mRNA measurement of IFN- $\gamma$ and IL-2 from immunized mice in different groups. C57BL/6 mice (five mice per group) were immunized three times with antigens OVA257-264 peptide, OVA, His-Ii-O257, or His-Ii-CT257 and total RNA was isolated. Optimized reverse transcription of RNA and amplification of specific cDNA were performed using PrimeScript ${ }^{\circledR}$ RT reagent Kit. Relative quantification of different cytokines on transcription level was determined by $\mathrm{SYBR}^{\circledR}$ Green I RT-PCR followed by $\Delta \Delta \mathrm{C}_{\mathrm{T}}$-analysis. RT-PCRs were performed in triplicate. Significant PCR fluorescent signals $\left(\mathrm{C}_{\mathrm{T}}\right)$ for IFN- $\gamma$ and IL-2 were normalized to a PCR fluorescent signal obtained from an endogenous reference ( $\beta$-actin). Comparative and relative quantification of gene products, normalized to $\beta$-actin and control, were calculated by: $2^{-\Delta \Delta C T}$. Significant difference compared with control mice $(\mathrm{N}=5, \mathrm{P}<0.05)$.

\section{Colocalization of $\mathrm{H}-2 \mathrm{~K}^{\mathrm{b}}$ with Ii constructs in the endocytic vesicle and on the plasma membrane}

To obtain a better understanding about the role of the epitope carrier of Ii in crosspresentation, we used CLSM to confirm the intracellular association of the Ii constructs with MHC class I molecules. We co-transfected COS7 cells with pEGFP-N1-H-2K ${ }^{\mathrm{b}}$ and pmCherry-C1-Ii/Ii variants. In transiently transfected COS7 cells, WT Ii molecules localized at, or near, the cell surface in most of the examined cells, with a fraction of molecules occurring in the large vesicles (Figure 3a). Both Ii-O257 and Ii-CT257 molecules showed almost identical intracellular distributions compared to WT Ii molecules (Figure 3b, c), because they contained a functional endosomal targeting signal in the $\mathrm{N}$-terminus. We then examined the localization of $\mathrm{H}-2 \mathrm{~K}^{\mathrm{b}}-\mathrm{GFP}$ molecules. Endogenously expressed $\mathrm{H}-2 \mathrm{~K}^{\mathrm{b}}-\mathrm{GFP}$ molecules were localized in a similar area to RFP-Ii/Ii variant molecules (Figure 3d-f). Colocalization was observed as an orange or yellow-orange color in the merged images, because of the combined green and red signals. This result demonstrated that a fraction of the $\mathrm{H}-2 \mathrm{~K}^{\mathrm{b}}$-GFP-containing vesicles was positive for WT Ii and Ii variant molecules (Figure 3g-i). Interestingly, we noted massive colocalization on the plasma membrane, indicating that the majority of Ii molecules are also physically associated with $\mathrm{H}-2 \mathrm{~K}^{\mathrm{b}}$ molecules on the cell membrane. Thus, we concluded that extensive $\mathrm{Ii} \cdot \mathrm{H}-2 \mathrm{~K}^{\mathrm{b}}$ complexes exist in the transfected cells. 


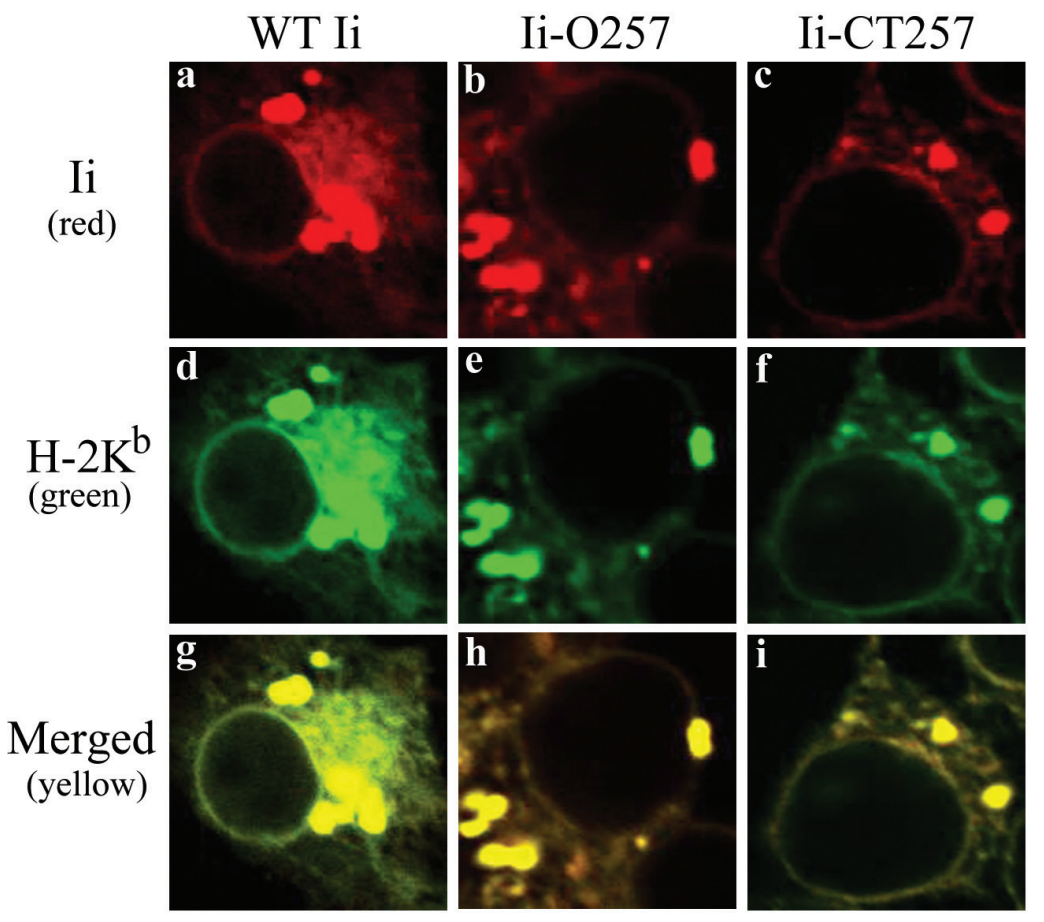

Figure 3. $\mathrm{H}-2 \mathrm{~K}^{\mathrm{b}}$. Ii complexes are found in endocytic vesicles and on the plasma membrane in co-transfected COS7 cells. Cells were transiently co-transfected with recombinant plasmids pmCherry-C1-Ii/li variants (Ii-O257, Ii-CT257) expressing RFP-Ii/Ii variants (red) and recombinant plasmid pEGFP-N1-H-2K $\mathrm{K}^{\mathrm{b}}$ expressing H-2K ${ }^{\mathrm{b}}-\mathrm{GFP}$ molecule (green). Cells were fixed $24 \mathrm{~h}$ later and observed using CLSM and x 60 oil objective. RFP-Ii/Ii variant molecules localized at or near the cell surface, with a fraction of molecules in the large vesicles (a-c). Localization of H-2K $\mathrm{K}^{\mathrm{b}}$-GFP molecules had similar features to Ii variants (d-f). Merged images of H-2K $\mathrm{K}^{\mathrm{b}}$-GFP and RFP-Ii/Ii variant cells represented in yellow showed that $\mathrm{H}-2 \mathrm{~K}^{\mathrm{b}}$. Ii complexes were formed both in endocytic vesicles and on the plasma membrane (g-i). Thus, RFP-Ii/Ii variant molecules co-localized with H-2K $\mathrm{K}^{\mathrm{b}}$-GFP molecules in an extensive manner in COS7 cells. These optically merged images are representative of most cells examined by CLSM. Yellow, colocalization of the green and red signal.

\section{Association of $\mathbf{H}-2 K^{b}$ with Ii variants in $\operatorname{COS7}$ cells}

We investigated whether the CLIP-substituted Ii and C-terminal truncation of this Ii chimer was also associated intracellularly with MHC class I molecules. Immunoprecipitation and Western blotting determined the interaction of Ii constructs and $\mathrm{H}-2 \mathrm{~K}^{\mathrm{b}}$ molecules in COS7 cells. As shown in Figure 4, WT Ii and Ii-O257 bound with relatively high affinity to $\mathrm{H}-2 \mathrm{~Kb}$ molecules. Likewise, Ii-CT257 was also coprecipitated with H-2Kb molecules. This observation was consistent with our previous observations that the N-terminal region of Ii containing F306 epitopes could bind to MHC class II molecules (Chen et al., 2012). These results indicated that, in addition to the CLIP region, the N-terminal flanking region of CLIP and DN residues might also play an important role in interacting with MHC class I molecules. As the Ii CLIP region occupies the peptide-binding region, the N-terminal functional segments of Ii appear to interact with MHC class I molecules near the cleft. 


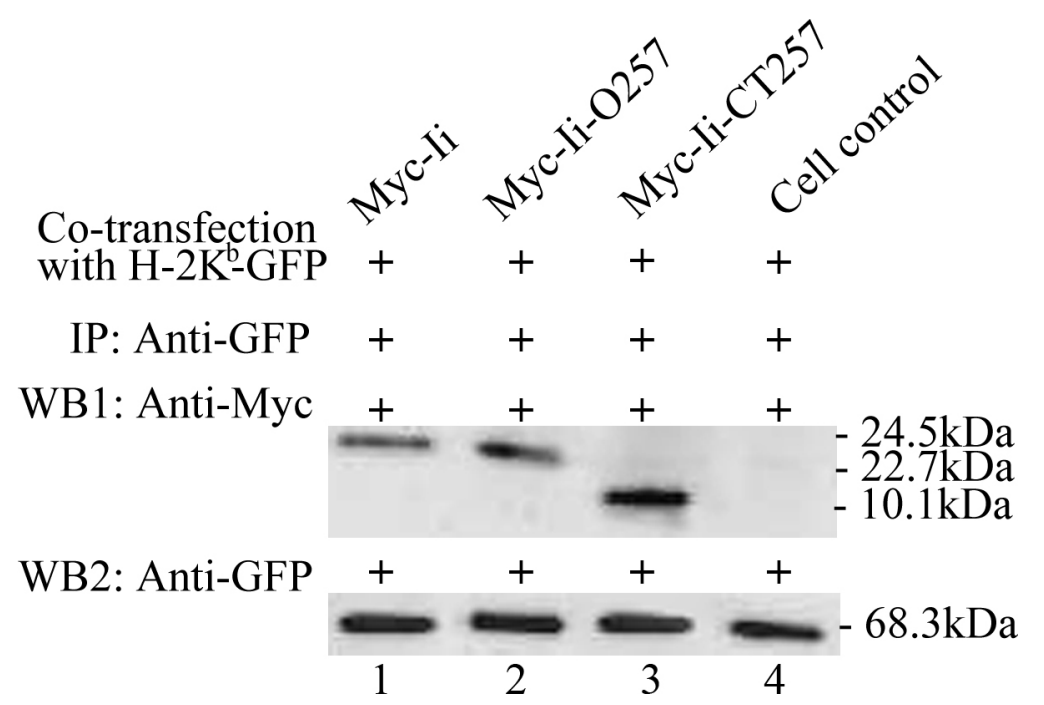

Figure 4. Binding of Ii and Ii variants to $\mathrm{H}-2 \mathrm{~K}^{\mathrm{b}}$ molecules. H-2K $\mathrm{K}^{\mathrm{b}}-\mathrm{GFP}$ was co-transfected with Ii-Myc, Ii-O257Myc and Ii-CT257-Myc in COS7 cells. Cell lysates were immunoprecipitated $48 \mathrm{~h}$ later with anti-GFP Tag mAb. Subsequently, the immune complexes (lanes 1-3) and controls (lane 4) were separated by 12\% SDS-PAGE under reducing conditions. Ii, Ii variants and $\mathrm{H}-2 \mathrm{~K}^{\mathrm{b}}$ molecules were detected by immunoblotting with anti-Myc tag $\mathrm{mAb}$ (WB1) or anti-GFP tag mAb (WB2). The fusion proteins had molecular sizes of $24.5 \mathrm{kDa}$ (Ii-Myc), $22.7 \mathrm{kDa}$ (IiO257-Myc), $10.1 \mathrm{kDa}(\mathrm{Ii}-\mathrm{CT} 257-\mathrm{Myc})$, and $68.3 \mathrm{kDa}\left(\mathrm{H}-2 \mathrm{~K}^{\mathrm{b}}-\mathrm{GFP}\right)$, in which the GFP tag had a molecular size of $27 \mathrm{kDa}$. The migration positions are indicated to the right.

\section{DISCUSSION}

Cross-presentation by DCs has a major role at generating effective primary CTL responses in vivo (Sigal et al., 1999; Lizee et al., 2003). Although Ii is classically recognized as a major chaperone in MHC class II presentation, Ii might also interact with MHC class I molecules (Cerundolo et al., 1992; Sugita and Brenner, 1995; Powis, 2006). Here, we confirmed the interaction of Ii and $\mathrm{H}-2 \mathrm{~K}^{\mathrm{b}}$ molecules. Moreover, Ii substantially contributed to the MHC class I CP pathway in DCs, while Ii-dependent CP was also observed to have a major role in the generation of responses to viral and cell-associated antigens (Basha et al., 2012).

In the current study, we demonstrated that C57BL/6 mice immunized with recombinant protein Ii-OVA257-264 elicited increased $\mathrm{CD}^{+} \mathrm{T}$ cell responses in vivo, compared to those in OVA257-264 peptide immunized mice. We determined that the Ii proteins were 10-15 times more efficient at activating $\mathrm{T}$ cells compared to peptides. The intracellular colocalization of $\mathrm{H}-2 \mathrm{~K}^{\mathrm{b}}$ with Ii chimers indicates that this effect was the result of enhanced MHC I processing and the presentation of chimeric Ii-OVA257-264, which was probably because of it being transported through the Ii protein pathway. This observation supported our hypothesis that the versatile Ii vector may be used to enhance the loading of exogenous CTL epitopes onto MHC class I molecules for CP.

One of the early events during MHC class I processing is the binding of the heavy chain to $\beta 2 \mathrm{~m}$ in the ER. This results in MHC class I stabilization, leading to appropriate folding and incorporation into the class I-peptide-loading complex, which is essential for efficient MHC 
class I-peptide association. The results of the immunoprecipitation analysis indicated that the Ii-O257 chimer binds to the $\mathrm{H}-2 \mathrm{~K}^{\mathrm{b}}$ peptide-binding cleft. Thus, early in biosynthesis, $\mathrm{H}-2 \mathrm{~K}^{\mathrm{b}}$ may assemble with the Ii chimer in the ER. The CLIP-substituted Ii chimer was considered to target the peptide directly at the groove of MHC class I. The binding of the Ii chimer to H-2 $\mathrm{K}^{\mathrm{b}}$ might promote the generation of high levels of stable and long-lasting H-2K ${ }^{\mathrm{b}}$-OVA257-264 complexes at this early stage. In addition, early formed $\mathrm{H}-2 \mathrm{~K}^{\mathrm{b}}-\mathrm{OVA} 257-264$ complexes would probably prevent other endogenously derived peptides from binding to the cleft when MHC class I molecules were within the ER. It is possible that stable H-2K $\mathrm{K}^{\mathrm{b}}$-OVA257-264 complexes are not formed when OVA257-264 peptide is exogenously added. After trafficking to endosomes, recombinant Ii protein is degraded, and the epitope peptide remains bound to MHC class I molecules. The presence of high numbers of CTL epitopes on MHC class I molecules dramatically enhanced the stimulation of $\mathrm{CD} 8^{+} \mathrm{T}$ cells.

An alternative explanation is that the MHC class I cytoplasmic tyrosine motif normally targets $\mathrm{MHC}$ class I molecules from the membrane being recycled to the $\mathrm{CP}$ compartments (Lizee et al., 2003). This action indicates the presence of an Ii-independent pathway, through which MHC class I molecules traffic through the endosomal compartments. We assume that a subset of Ii chimers might gain direct access to endosomes. Once there, a regulated degradation of Ii chimers yields a high level of epitope peptides. Such a large quantity of peptides would increase the chance of capture by endocytosed MHC class I molecules, which then recycle back to the cell surface for $\mathrm{CP}$ to $\mathrm{T}$ cells.

Interestingly, in this study, we showed that Ii-CT257 could associate with the H-2K molecule. This observation indicates that the N-terminal functional regions of Ii bind stably and with high affinity to MHC class I molecules, without the C-terminus trimerization region. Despite the deletion of the CLIP region, the loss of affinity for the peptide-binding site is complemented by OVA257-264 peptide in this Ii mutant. The TM of Ii also helps form $\alpha \beta /$ Ii trimers (Ashman and Miller, 1999). In addition, the Ii-key segment of the Ii protein acts as an allosteric site on MHC class II molecules to facilitate the charging of antigenic peptides (Kallinteris et al., 2006), while DN facilitates the effective and stable binding of peptides to MHC class II molecules (Chen et al., 2012). Consequently, we speculate that the TM domain might also bind to sites in MHC class I molecules outside the peptide-binding groove, and that Ii-key and DN segments facilitate OVA257-264 epitope loading onto MHC class I molecules. Further experiments are required to elucidate this mechanism.

Overall, our data indicate a new minimal functional fragment of the Ii vector. The $\mathrm{N}$-terminal region of the Ii-epitope fusion protein employed in this study could present the binding of specific epitopes to MHC class I molecules by CP. Future work should focus on elucidating the relevant mechanisms and better characterizing the dynamic nature of CP. Understanding these issues will ultimately lead to the design of new vaccines against cancer and viruses.

In conclusion, through the use of confocal microscopy and co-immunoprecipitation, we demonstrated that the N-terminal flanking region of Ii contains an intracellular OVA257264 chimer bound to $\mathrm{H}-2 \mathrm{~K}^{\mathrm{b}}$ molecules. These results indicate that the Ii-OVA257-264 chimer could be involved in the route of MHC class I molecule $\mathrm{CP}$, and promote the loading of OVA257-264 epitopes onto MHC class I molecules in vivo, resulting in enhanced specific in vivo $\mathrm{CD}^{+} \mathrm{T}$ cell responses. This approach might be feasible for use in the induction of immunity against infectious agents or tumors. 


\section{ACKNOWLEDGMENTS}

Research supported by a grant from the National Natural Science Foundation of China, Beijing (\#31201888, \#31101846).

\section{REFERENCES}

Ashman JB and Miller J (1999). A role for the transmembrane domain in the trimerization of the MHC class II-associated invariant chain. J. Immunol. 163: 2704-2712.

Bakke O and Dobberstein B (1990). MHC class II-associated invariant chain contains a sorting signal for endosomal compartments. Cell 63: 707-716.

Basha G, Omilusik K, Chavez-Steenbock A, Reinicke AT, et al. (2012). A CD74-dependent MHC class I endolysosomal cross-presentation pathway. Nat. Immunol. 13: 237-245.

Bevan MJ (1976). Minor H antigens introduced on H-2 different stimulating cells cross-react at the cytotoxic T cell level during in vivo priming. J. Immunol. 117: 2233-2238.

Brink N, Szamel M, Young AR, Wittern KP, et al. (2000). Comparative quantification of IL-1beta, IL-10, IL-10r, TNFalpha and IL-7 mRNA levels in UV-irradiated human skin in vivo. Inflamm. Res. 49: 290-296.

Cerundolo V, Elliott T, Elvin J, Bastin J, et al. (1992). Association of the human invariant chain with H-2 Db class I molecules. Eur. J. Immunol. 22: 2243-2248.

Chen F, Meng F, Pan L, Xu F, et al. (2012). Boosting immune response with the invariant chain segments via association with non-peptide binding region of major histocompatibility complex class II molecules. BMC Immunol. 13: 55.

Fujii S, Senju S, Chen YZ, Ando M, et al. (1998). The CLIP-substituted invariant chain efficiently targets an antigenic peptide to HLA class II pathway in L cells. Hum. Immunol. 59: 607-614.

Gao M, Wang HP, Wang YN, Zhou Y, et al. (2006). HCV-NS3 Th1 minigene vaccine based on invariant chain CLIP genetic substitution enhances CD4(+) Th1 cell responses in vivo. Vaccine 24: 5491-5497.

Heath WR and Carbone FR (2001). Cross-presentation, dendritic cells, tolerance and immunity. Annu. Rev. Immunol. 19: 47-64.

Kaleab B, Ottenoff T, Converse P, Halapi E, et al. (1990). Mycobacterial-induced cytotoxic T cells as well as nonspecific killer cells derived from healthy individuals and leprosy patients. Eur. J. Immunol. 20: 2651-2659.

Kallinteris NL, Powell D, Blackwell CE, Kim M, et al. (2006). Ii-Key/MHC class II epitope peptides as helper T cell vaccines for cancer and infectious disease. Front. Biosci. 11: 46-58.

Langenkamp A, Casorati G, Garavaglia C, Dellabona P, et al. (2002). T cell priming by dendritic cells: thresholds for proliferation, differentiation and death and intraclonal functional diversification. Eur. J. Immunol. 32: 2046-2054.

Larsson M, Fonteneau JF and Bhardwaj N (2001). Dendritic cells resurrect antigens from dead cells. Trends Immunol. 22: $141-148$

Lehner PJ and Cresswell P (2004). Recent developments in MHC-class-I-mediated antigen presentation. Curr. Opin. Immunol. 16: 82-89.

Lizee G, Basha G, Tiong J, Julien JP, et al. (2003). Control of dendritic cell cross-presentation by the major histocompatibility complex class I cytoplasmic domain. Nat. Immunol. 4: 1065-1073.

Ma X, Serna A, Xu RH and Sigal LJ (2009). The amino acid sequences flanking an antigenic determinant can strongly affect MHC class I cross-presentation without altering direct presentation. J. Immunol. 182: 4601-4607.

Norbury CC and Sigal LJ (2003). Cross priming or direct priming: is that really the question? Curr. Opin. Immunol. 15: $82-88$.

Powis SJ (2006). CLIP-region mediated interaction of Invariant chain with MHC class I molecules. FEBS Lett. 580: 3112-3116.

Princiotta MF, Finzi D, Qian SB, Gibbs J, et al. (2003). Quantitating protein synthesis, degradation, and endogenous antigen processing. Immunity 18: 343-354.

Sigal LJ, Crotty S, Andino R and Rock KL (1999). Cytotoxic T-cell immunity to virus-infected non-haematopoietic cells requires presentation of exogenous antigen. Nature 398: 77-80.

Sugita M and Brenner MB (1995). Association of the invariant chain with major histocompatibility complex class I molecules directs trafficking to endocytic compartments. J. Biol. Chem. 270: 1443-1448.

Townsend AR, Gotch FM and Davey J (1985). Cytotoxic T cells recognize fragments of the influenza nucleoprotein. Cell 42: 457-467.

Townsend AR, Rothbard J, Gotch FM, Bahadur G, et al. (1986). The epitopes of influenza nucleoprotein recognized by 
cytotoxic T lymphocytes can be defined with short synthetic peptides. Cell 44: 959-968.

van Bergen J, Schoenberger SP, Verreck F, Amons R, et al. (1997). Efficient loading of HLA-DR with a T helper epitope by genetic exchange of CLIP. Proc. Natl. Acad. Sci. U. S. A. 94: 7499-7502.

van Luijn MM, van de Loosdrecht AA, Lampen MH, van Veelen PA, et al. (2012). Promiscuous binding of invariant chain-derived CLIP peptide to distinct HLA-I molecules revealed in leukemic cells. PLoS One 7: e34649.

Yewdell JW, Norbury CC and Bennink JR (1999). Mechanisms of exogenous antigen presentation by MHC class I molecules in vitro and in vivo: implications for generating CD8+ T cell responses to infectious agents, tumors, transplants, and vaccines. Adv. Immunol. 73: 1-77.

Zinkernagel RM and Hengartner H (2001). Regulation of the immune response by antigen. Science 293: 251-253. 